\title{
Prophylaxis and Early Detection of HPV-Related Neoplasia
}

\author{
Herbert Pfister, Cologne, Editor \\ Monographs in Virology. S. Karger \\ Detection of HPV DNA and RNA
}

\author{
Hans Ikenberg, Germany
}

\begin{abstract}
The balance between analytical (low) and clinical (high) sensitivity is crucial for the specificity of a routine HPV test as limited specificity will be harmful due to unnecessary treatment of healthy women. Up to now HPV diagnostics is mainly based on DNA detection for which target and signal amplification methods are available. PCR techniques can be divided into type-specific and consensus PCRs. Due to its high clinical sensitivity and its relatively high specificity the $\mathrm{HC} 2$ test is still regarded as the gold standard in routine HPV testing. It hybridizes 13 (near) full-length stabilized RNA probes of high-risk HPV types to denatured target DNA followed by detection via antibodies and chemiluminescence. To avoid costly validation studies for each new HPV test standards for evaluation have been defined. Recently several new HPV detection assays have been commercialized. They all show promising data in first published studies but still await full validation according to the criteria mentioned above. Among them only the cobas HPV test has already been fully validated for use in triage and as adjunct to cytology. HPV 16 and 18 confer a much higher risk for development of a CIN 2+ compared to the other HPV high-risk types. It is therefore appropriate to test for these HPV types independently. Apart from that testing for individual HPV types is of very limited clinical value up to now.HPV RNA testing is a promising option with potentially higher specificity. As a first system, the APTIMA test has now received an FDA approval.
\end{abstract}

\section{Background}

While cytology fails to detect prevalent CIN 2+ in a first approach in half of the cases (McCrory D 1999) molecular HPV diagnostics is able to achieve this goal in up to $99 \%$. Unlike morphology it also predicts the risk of developing CIN 2+. Otherwise the presence of HPV DNA often is transient if not even contamination (Schiffman, Wentzensen et al. 2011). Therefore standardized methods of HPV detection are of utmost importance to achieve clinically relevant results.

Except in some rare conditions only HPV high-risk testing is regarded of clinical value. In this chapter HPV testing means identification of HPV high-risk types which are defined by their association with cancer. In the future HPV diagnostics may become helpful also for diagnostics of oral, laryngeal and pharyngeal (D'Souza, Kreimer et al. 2007) as well as anal (Frisch, Glimelius et al. 1997) neoplasias. To date it is clinically almost solely used in cervical lesions.

Today HPV diagnostics is a routine tool in three areas. First, triage of cytologically borderline (Wright, Cox et al. 2002) or low grade (Wright, Massad et al. 2007) abnormalities. Second, as a test of cure after therapy of CIN (Zielinski, Bais et al. 2004). Third, HPV testing as an adjunct to cytology is recommended in major guidelines (Saslow, Runowicz et al. 2002) and meanwhile the replacement of cytology as primary screening method by HPV is intensively discussed (Katki, Kinney et al. 2011).

The detection of HPV is not always indicative of the disease resulting from the infection. A certain amount of virus has to be present for a certain time in order to induce cervical neoplasia (Josefsson, Magnusson et al. 2000; Snijders, van den Brule et al. 2003). Hence transient infections with HPV and low amounts of virus are clinically irrelevant. Routine HPV testing requires a clinically defined cut-off value of a detection system to

14. Kongres udruženja patologa i citologa Srbije sa međunarodnim učešćem, Beograd 14-16 juna, 2012

14 th Congress of Serbian Association of Pathologists and Cytologists with international participation, Belgrade 14-16 June, 2012 
avoid HPV positivities which compromise specificity and cause unnecessary further diagnostic procedures and treatments. It is rare that a 12 year old diagnostic test like HC2 is regarded as gold-standard and the reference of a major guideline. The fact that this holds in clinical HPV testing points to a special situation with distinct technical requirements not easy to meet.

\section{Methods of HPV detection}

Although in-situ-hybridization is able to locate the viral DNA its low sensitivity and lacking ability for highthroughput preclude a routine use (Hesselink, van den Brule et al. 2004). Any routine diagnostic use of HPV protein detection is excluded by the fact that the HPV oncogenes E6 and E7 are expressed in very differential levels and no validated tests for their detection are available. The inconsistent seroconversion rate even in persons with high grade cervical lesions precludes any routine serology tests (Wang, Schiffman et al. 2003).

Therefore only HPV DNA and (to a lesser extent) RNA assays are currently available for clinical applications. Because HPV DNA is present in productive as well as in transforming infections but also potentially as a contamination its detection can primarily not inform about the clinical importance of this finding.

Technically for HPV DNA testing target and signal amplification methods are available. PCR techniques can be divided into type-specific and consensus (general primer) PCRs. The products of consensus PCRs can also be used for genotyping, eg by hybridizing them to multiple HPV types fixed on a membrane strip (Linear Array) or to a DNA chip (Papillocheck).

\section{PCR}

Several PCRs for HPV detection are commercially available. The most widely distributed is meanwhile the cobas assay, a realtime consensus PCR which covers 14 HPV high-risk types and additionally differentiates HPV 16 and 18 (Roche Molecular Diagnostics, Pleasanton, CA; see below). It replaced the Amplicor test which never met all criteria for routine use.

The linear array assay is a type-specific method detecting 37 high- and low-risk types (Roche) while the SPF10 assay (Kleter, van Doorn et al. 1999) (Innogenetics, Gent, Belgium), the most sensitive HPV assay available, identifies 28 types. The most common PCR techniques only available for scientific applications are the GP5+/6+ (Jacobs, Snijders et al. 1997) and the PGMY (Gravitt, Peyton et al. 2000) general primer sets. An interesting multiplex variant of GP5+/6+ with Luminex detection with more even coverage of up to 100 different HPV types has been recently presented (Schmitt, Bravo et al. 2006). All these tests target the L1 region of the HPV genome with resulting amplicons from 65 to $450 \mathrm{bp}$ length. Enzyme-immuno assays or reverse line blot assays are used as detection systems. The analytical sensitivity varies from less than 10 copies with SPF10 primers with purified DNA to around 1000 copies with the GP5+/ 6+ primers in crude extracts (Snijders, van den Brule et al. 2003). Numerous commercial labs have made up their own PCRs which are at best internally validated, generally have not been investigated in scientific studies and are therefore less suitable for clinical use.

The analytical sensitivity of PCR can go down to some copies of HPV DNA. Surprisingly that is not reflected in a similar clinical sensitivity. Only a few larger studies showed an ability to identify more than $95 \%$ of CIN 2+ lesions and the median sensitivity of HPV PCR was reported to be $82 \%$ in 16 studies (Lorincz and Smith 2006). This can be explained by several factors. Primers usually targeting the L1 region of the HPV genome may lack to bind in up to 7\% of high grade lesions and cancers that have lost this region (Karlsen, Kalantari et al. 1996). Other reasons are random partial inhibition (which is not necessarily indicated by internal controls) and competition effects if several HPV types are present (Qu, Jiang et al. 1997). One challenge with consensus HPV PCRs is to obtain an equal and regular level of detection of different HPV types as shown by the range of sensitivity of the GP5+/6+ assay depending on the HPV type (Jacobs, Snijders et al. 1997). Another challenge is the adjustment of a reliable cut-off, which is even a major point in ultra-sensitive type-specific PCRs. 


\section{Signal amplification}

Two signal amplification technologies (HC2 test, Qiagen, Gaithersburg, MD; Cervista, Hologic, Bedford, MA) are on the market.

The HC2 test hybridizes 13 (near) full-length stabilized RNA probes of high-risk HPV types to denatured HPV target DNA followed by detection via antibodies and chemiluminescence. The threshold value of the system is $1 \mathrm{pg} / \mathrm{ml}$ which corresponds to around 5.000 copies of HPV DNA per test (Lorincz and Smith 2006). It is very robust in the pre-analytical phase, has a simple sample preparation and requires no separate rooms for different work steps. Up to now only partial automation is available. The inter-laboratory variation of the HC2 test is very low and its results are highly reproducible (Castle, Wheeler et al. 2004). Respective data on PCR are less consistent (Quint, Pagliusi et al. 2006). One theoretical drawback of the HC2 test is the lack of a control for the presence of human cellular material. In routine application this seems to be of minor importance as it shows a sensitivity of up to $99 \%$ for CIN $3+$ measured on a histology gold standard (Bohmer, van den Brule et al. 2003) (Castle, Cox et al. 2008) and the low rate of specimens ( 1\%) without amplification of a house-keeping gene in major studies (Castle, Gutierrez et al. 2011; Youens, Hosler et al. 2011). Additionally risk estimates were hardly affected by adjusting for the amount of a housekeeping gene in a PCR system (van Duin, Snijders et al. 2002). Another potential problem may be a cross reaction with a couple of low-risk HPV types which was determined to be $7.8 \%$ of all positive HC2 results (Castle, Solomon et al. 2008). Because some of them are regarded in fact as being of intermediate risk, this may even contribute to the high clinical sensitivity of the test (Castle, Solomon et al. 2008). While the HC2 test out of the vial of the ThinPrep liquidbased cytology has been approved by the FDA there are hints that the performance of the system under these conditions (which requires an elaborate transformation process) is somewhat poorer than from the standard medium (Carozzi, Del Mistro et al. 2005).

The clinical sensitivity of the HC2 test is very high, in 26 trials worldwide its median was $94 \%$ (Lorincz and Smith 2006). More than 200.000 women have been included in screening studies with this assay published in peer reviewed journals. This figure exceeds by far the data available for any single PCR method. Significant differences in performance were observed between HPV screening studies conducted in Europe and Northern America reaching up to $99 \%$ sensitivity compared to investigations in developing countries. Here regularly the sensitivity was 20-30\% lower which might be explained by weaknesses of regional colposcopy and histology leading to deficits in gold standard definition (Sankaranarayanan, Chatterji et al. 2004). Though in "real life" the clinical sensitivity even under optimized conditions will not exceed $95-98 \%$ due to sampling errors or minor technical variations (Lorincz and Smith 2006).

Qiagen developed careHPV, a basic version of HC2 without need for running water and main electricity with a turn-around time of only 2.5 hours. That allows further diagnostic or therapeutic procedures in the same visit. A study in China showed $90 \%$ sensitivity for CIN 2+ (Qiao, Sellors et al. 2008). Further trials are ongoing and a broad roll-out in developing countries is intended.

A second signal amplification test (Cervista, Hologic, Bedford, MA) gained FDA approval in 2009. It uses two isothermal reactions with a proprietary technology (Invader) which detects 14 high-risk HPV types as a group and in addition HPV 16 and 18 together. First data from the package insert pointed to a much lower specificity than eg of HC2 and were negatively discussed (Kinney, Stoler et al. 2010). Newly published data showed a similar sensitivity and specificity as with HC2 in a NILM (Quigley, Potter et al. 2011); (Youens, Hosler et al. 2011) and ASC-US population (Einstein, Martens et al. 2010; Quigley, Potter et al. 2011).

\section{The central role of specificity}

The major problem of routine HPV diagnostics is its relatively low specificity which is limited even with non-DNA-amplifying methods. This restricts its use in a screening approach to women over 30 years (Saslow, Runowicz et al. 2002). Below this age testing is regarded as useful in case of cytological and/or colposcopic abnormality (triage) and after therapy of CIN as a test of cure (Wright, Cox et al. 2002). But even in this triage setting the revised ASCCP guidelines in the US discourage HPV testing in the below 20s due to very

14. Kongres udruženja patologa i citologa Srbije sa međunarodnim učešćem, Beograd 14-16 juna, 2012

14 th Congress of Serbian Association of Pathologists and Cytologists with international participation, Belgrade 14-16 June, 2012 
high remission rates in this age group (Wright, Massad et al. 2007). Currently HPV testing is regarded more useful i.e. predictive the older the tested women are. If however the appropriate test is used in the appropriate age group screening by HPV DNA testing is able to reach the specificity of cytology as demonstrated by 5 of 26 studies reviewed in a HTA (Mittendorf, Nocon et al. 2007).

The specificity can be increased by raising the viral load cut-off. This can be achieved more easily with signal-amplifying methods than with PCR. Studies here show a slightly lower (Lorincz and Smith 2006) or unchanged (Guyot, Karim et al. 2003; Hesselink, Bulkmans et al. 2006) sensitivity, while in either case the specificity was raised. A recent systematic review underlined these findings (Rebolj, Bonde et al. 2011).

Even though the importance of a minimal viral load for the development of HPV induced disease is obvious there seems to be no clear-cut association between quantitative (real-time PCR) or semiquantitative (HC2) measurements of viral load and prognostic potential at a level above the detection limit of the HC2 test (Bory, Cucherousset et al. 2002; Lorincz, Castle et al. 2002; Snijders, van den Brule et al. 2003)

A trade-off between sensitivity and specificity also limits an extension of the number of types covered by clinical HPV tests. The inclusion of very rarely occurring types beyond the 13-14 included in most tests increases sensitivity minimally, while leading to an unproportional decrease in specificity (Schiffman, Khan et al. 2005).

The main issue when using HPV testing as an adjunct to cytological screening is the rate of women positive for high-risk HPV in the absence of cytological abnormalities. This rate is usually very low for women of 30 years and older. Among more than 800.000 tests in nearly 600.000 women in California tested with the HC2 system the rate equalled $3.99 \%$ with only about one third of them remaining positive over one year, thus leaving less than $1.5 \%$ for colposcopy (Castle, Fetterman et al. 2009). An even lower rate (1.9\%) was observed among cytologically normal women screened with liquid-based cytology and computer-assistance (Bansal, Austin et al. 2009). That means that with even an ASC-US rate of just 3\% (where at maximum half of the cases will be HPV positive) the total number of women scheduled for colposcopy will not increase whereas this group now comprises also all cytologically false-negatives.

The crucial criterion for the clinical value of a routine HPV test is not its analytical but its clinical sensitivity. Because limited specificity will be harmful via unnecessary treatment of healthy women also clinical sensitivity has to be traded off with specificity (Kinney, Stoler et al. 2010). The observance of a well defined diagnostic threshold must be guaranteed. Up to now this has only been proven in large-scale studies for the $\mathrm{HC} 2$ and the cobas test. For several reasons as stated above this objective is rather complicated to achieve for PCR techniques.

\section{A guideline for new HPV tests}

It is indispensable that new tests for routine HPV testing prove a balance between clinical sensitivity and specificity. To avoid costly validation studies for each new HPV test standards for evaluation have been defined by leading experts on the field (Meijer, Berkhof et al. 2009). These standards of noninferiority are based on the results of numerous large screening studies with HC2 and the GP5+/6+ PCR which set the standards for cut-off, sensitivity and specificity in clinical use. A new HPV test among women above 30 years should reach a relative sensitivity of $90 \%$ and a relative specificity of $98 \%$ of that of the HC2 test. To test for that around $60 \mathrm{HPV}$-positive probes of CIN2+ and around $800 \mathrm{HPV}$-negative specimens are needed. Additionally an intra- and interlaboratory concordance of at least $87 \%$ in 500 specimens is requested.

\section{New commercial HPV tests}

2011 data from the largest clinical HPV study conducted until now have been published assessing the cobas HPV test (Roche). The ATHENA trial, comprising over 47.000 women proved performance comparable to the HC2 test in triage of women with ASC-US cytology (Stoler, Wright et al. 2011) and high sensitivity for CIN2+ in cytologically normal women (Castle, Stoler et al. 2011). The test has further met the criteria of the 
guideline for new HPV tests (Heideman, Hesselink et al. 2011). Meanwhile the cobas test has received FDA approval for triage and co-testing with cytology (each from the Preservcyt LBC vial).

Recently also other new HPV detection assays have been commercialized. The Abbott Real Time High Risk HPV Test (Abbott Molecular, Wiesbaden, Germany) is a PCR DNA assay which detects 14 high-risk HPV types as a group-specific test and separately HPV 16 and 18. In a first comparison it showed similar performance as HC2 and Linear Array (Cuzick, Ambroisine et al. 2010). As did the B\&D Viper HPV realtime PCR which detects 14 high-risk HPV types and discriminates 7 of them (Castle, Gutierrez et al. 2011). A DNA chip test for the type-specific detection of 18 high-risk and 6 low-risk HPV types which is based on the detection of E1 sequences (Papillocheck, greiner bio-one, Frickenhausen, Germany) was found clinically compatible with the GP5+/6+ assay (Hesselink, Heideman et al. 2010).

\section{HPV Genotyping}

Several studies showed a significantly higher risk for development of a CIN $2+$ among women positive for HPV 16, 18 and 45 (which is closely related to HPV 18) compared to positivity for other HPV high-risk types. This was valid for cytologically normal women (Khan, Castle et al. 2005; Castle, Rodriguez et al. 2009) as well as with borderline cytologic findings (Wheeler, Hunt et al. 2006). It is therefore appropriate to test for these HPV types independently. This makes only sense after or in parallel with a HPV high-risk basic test because clinically relevant cases positive for high-risk types beside 16,18 and 45 would otherwise be missed.

It is generally accepted that a diagnosis of individual HPV types is of scientific interest but its clinical value is currently very limited. First, the risk potential of other HPV types than 16, 18 and 45 is not well defined and seems to be similar (Khan, Castle et al. 2005), second, even if this potential would be better defined it might be difficult to implement the routine application of complex type-specific algorithms. Already at present the follow-up of HPV positivity in clinical practice is rather challenging. Another problem with routine full HPV typing is the high analytical sensitivity and consecutively lower specificity when using the PCR assays which are only available for that purpose. On the other hand detection of HPV 16, 18 and 45 can be achieved by a variant of the HC2 test (which is currently under FDA review) with the same cut-off as the basic test as well as HPV 16 and 18 can be detected separately with some newer tests like cobas or Cervista.

\section{HPV RNA Testing}

A logic approach to overcome some limitations in HPV diagnostics is testing for HPV RNA because elevated expression of viral oncogenes E6 and E7 is associated with malignant transformation by high-risk HPV. Due to non-transforming activities of HPV oncogenes and subsequent transcription also in non-neoplastic lesions and the general instability of RNA HPV mRNA analytics is more complicated than initially expected. First promising results (Molden, Kraus et al. 2005) of a commercial assay (pretectproofer ${ }^{\mathrm{TM}}$, norchip, Klokkarstua/Norway now Nuclisense ${ }^{\mathrm{TM}}$, Biomérieux, Marcy L'Étoile/France) have not be confirmed. In the PREDICTORS study (Szarewski, Ambroisine et al. 2008) the sensitivity of this test for CIN 2+ was only $73,6 \%$, beside other reasons probably due to the fact that it targets only five HPV types. However, it is not finally determined whether lacking HPV mRNA expression might also indicate high grade disease without the potential for progression. Another HPV mRNA test, the APTIMA HPV test (Genprobe, San Diego, CA) detects 14 high-risk HPV types as a group and is run on a fully automated system. Data point to a similar sensitivity and a higher specificity of the APTIMA test as for DNA detection assays (Castle, Dockter et al. 2007; Szarewski, Ambroisine et al. 2008). A promising aspect of the system is that no RNA isolation is required and sealed vials are used. Late in 2011 it received an FDA approval, joining the HC2, Cervista, and cobas tests. Very recently a new approach applying several marker transcripts showed high sensitivity for grading HPV 16 positive cervical lesions (Schmitt, Dalstein et al. 2010). A first systematic review attested HPV RNA testing diagnostic potential but saw the need for further studies (Burger, Kornor et al. 2011).

14. Kongres udruženja patologa i citologa Srbije sa međunarodnim učešćem, Beograd 14-16 juna, 2012

14 th Congress of Serbian Association of Pathologists and Cytologists with international participation, Belgrade 14-16 June, 2012 
Tab. 1. Test systems for the detection of HPV DNA and RNA

\begin{tabular}{|c|c|c|c|c|c|c|}
\hline Name & Producer & Technology & Target sequence & HPV types & Genotyping & Approval \\
\hline \multicolumn{7}{|l|}{ HPV DNA } \\
\hline Amplicor & Roche & PCR & L1 & $13 \mathrm{ca}$ & no & $\mathrm{CE}$ \\
\hline careHPV & Qiagen & Signal amp & $\begin{array}{l}\text { (part) full } \\
\text { genome }\end{array}$ & $14 \mathrm{ca}$ & no & $\begin{array}{c}\text { WHO } \\
\text { prequalification }\end{array}$ \\
\hline Cervista & Hologic & Signal amp & L1 & $14 \mathrm{ca}$ & HPV $16+18$ & $\mathrm{FDA}+\mathrm{CE}$ \\
\hline cobas & Roche & Realtime PCR & L1 & $14 \mathrm{ca}$ & HPV $16+18$ & $\mathrm{FDA}+\mathrm{CE}$ \\
\hline GP 5+/6+ & non commercial & PCR & L1 & $14 \mathrm{ca}$ & no & no \\
\hline $\mathrm{HC} 2$ & Qiagen & Signal amp & $\begin{array}{l}\text { (part) full } \\
\text { genome }\end{array}$ & $13 \mathrm{ca}$ & HPV $16+18$ & $\mathrm{FDA}+\mathrm{CE}$ \\
\hline Inno-LiPA & Innogenetics & PCR & L1 & $13 \mathrm{ca}+15 \mathrm{nca}$ & yes & $\mathrm{CE}$ \\
\hline Linear Array & Roche & PCR & L1 & $14 \mathrm{ca}+23 \mathrm{nca}$ & yes & $\mathrm{CE}$ \\
\hline $\begin{array}{l}\text { Multiplex HPV } \\
\text { Genotyping Kit }\end{array}$ & Multimetrix & PCR & L1 & $13 \mathrm{ca}+11 \mathrm{nca}$ & yes & \\
\hline Papillocheck & Greiner bioone & PCR & E1 & $13 \mathrm{ca}+11 \mathrm{nca}$ & yes & $\mathrm{CE}$ \\
\hline $\begin{array}{c}\text { RealTime HR } \\
\text { HPV }\end{array}$ & Abbott & Realtime PCR & L1 & $14 \mathrm{ca}$ & HPV $16+18$ & $\mathrm{CE}$ \\
\hline BD Viper HPV & $B \& D$ & Realtime PCR & L1 & $14 \mathrm{ca}$ & $\begin{array}{c}\text { HPV 16, 18, 31, } \\
45,51,52,59\end{array}$ & \\
\hline \multicolumn{7}{|l|}{ HPV RNA } \\
\hline APTIMA & Genprobe & TMA & E6/E7 mRNA & $14 \mathrm{ca}$ & $\begin{array}{c}\text { no } \\
\text { HPV } 16+18 \\
\text { planned }\end{array}$ & $\mathrm{CE}+\mathrm{FDA}$ \\
\hline $\begin{array}{c}\text { Nuclisens EasyQ } \\
\text { HPV }\end{array}$ & Biomérieux & NASBA & E6/E7 mRNA & $\begin{array}{c}\text { HPV } \\
16,18,31,33,45\end{array}$ & yes & $\mathrm{CE}$ \\
\hline $\begin{array}{c}\text { HPV } 16 \\
\text { transcriptome }\end{array}$ & non commercial & mRNA analysis & $\begin{array}{c}\text { E1/4/6+ L1 } \\
\text { mRNA }\end{array}$ & 16 & yes & \\
\hline
\end{tabular}

Ca: carcinogenic; CE: EU-registration; FDA: Food and Drug Administration approval; nac: non carcinogenic; NASBA: Nucleic acid sequence-based amplification; Signal amp: signal amplification; TMA: Transcription-mediated amplification; WHO: World Health Organization

\section{References}

Bansal, M., R. M. Austin, et al. (2009). "High-risk HPV DNA detected in less than 2\% of over 25,000 cytology negative imaged liquid-based Pap test samples from women 30 and older." Gynecol Oncol 115(2): 257-261.

Bohmer, G., A. J. van den Brule, et al. (2003). "No confirmed case of human papillomavirus DNA-negative cervical intraepithelial neoplasia grade 3 or invasive primary cancer of the uterine cervix among 511 patients." Am J Obstet Gynecol 189(1): 118-120.

Bory, J. P., J. Cucherousset, et al. (2002). "Recurrent human papillomavirus infection detected with the hybrid capture II assay selects women with normal cervical smears at risk for developing high grade cervical lesions: a longitudinal study of 3,091 women." Int J Cancer 102(5): 519-525.

Burger, E. A., H. Kornor, et al. (2011). "HPV mRNA tests for the detection of cervical intraepithelial neoplasia: a systematic review." Gynecol Oncol 120(3): 430-438.

Carozzi, F. M., A. Del Mistro, et al. (2005). "Reproducibility of HPV DNA Testing by Hybrid Capture 2 in a Screening Setting.” Am J Clin Pathol 124(5): 716-721.

Castle, P. E., J. T. Cox, et al. (2008). “An analysis of high-risk human papillomavirus DNA-negative cervical precancers in the ASCUS-LSIL Triage Study (ALTS).” Obstet Gynecol 111(4): 847-856.

Castle, P. E., J. Dockter, et al. (2007). “A cross-sectional study of a prototype carcinogenic human papillomavirus E6/E7 messenger RNA assay for detection of cervical precancer and cancer.” Clin Cancer Res 13(9): 2599-2605. 
Castle, P. E., B. Fetterman, et al. (2009). "Five-year experience of human papillomavirus DNA and Papanicolaou test cotesting." Obstet Gynecol 113(3): 595-600.

Castle, P. E., E. C. Gutierrez, et al. (2011). "Evaluation of a new DNA test for detection of carcinogenic human papillomavirus.” J Clin Microbiol 49(8): 3029-3032.

Castle, P. E., A. C. Rodriguez, et al. (2009). "Short term persistence of human papillomavirus and risk of cervical precancer and cancer: population based cohort study." BMJ 339: b2569.

Castle, P. E., D. Solomon, et al. (2008). “Human papillomavirus genotype specificity of hybrid capture 2.” J Clin Microbiol 46(8): 2595-2604.

Castle, P. E., M. H. Stoler, et al. (2011). "Performance of carcinogenic human papillomavirus (HPV) testing and HPV16 or HPV18 genotyping for cervical cancer screening of women aged 25 years and older: a subanalysis of the ATHENA study." Lancet Oncol 12(9): 880-890.

Castle, P. E., C. M. Wheeler, et al. (2004). “Interlaboratory reliability of Hybrid Capture 2.” Am J Clin Pathol 122(2): 238-245.

Cuzick, J., L. Ambroisine, et al. (2010). "Performance of the Abbott RealTime high-risk HPV test in women with abnormal cervical cytology smears.” J Med Virol 82(7): 1186-1191.

D’Souza, G., A. R. Kreimer, et al. (2007). “Case-control study of human papillomavirus and oropharyngeal cancer.” N Engl J Med 356(19): 1944-1956.

Einstein, M. H., M. G. Martens, et al. (2010). "Clinical validation of the Cervista HPV HR and 16/18 genotyping tests for use in women with ASC-US cytology." Gynecol Oncol 118(2): 116-122.

Frisch, M., B. Glimelius, et al. (1997). “Sexually transmitted infection as a cause of anal cancer.” N Engl J Med 337(19): 1350-1358.

Gravitt, P. E., C. L. Peyton, et al. (2000). "Improved amplification of genital human papillomaviruses.” J Clin Microbiol 38(1): 357-361.

Guyot, A., S. Karim, et al. (2003). "Evaluation of adjunctive HPV testing by Hybrid Capture II in women with minor cytological abnormalities for the diagnosis of CIN2/3 and cost comparison with colposcopy.” BMC Infect Dis 3: 23.

Heideman, D. A., A. T. Hesselink, et al. (2011). "Clinical validation of the cobas(R)4800 HPV Test for cervical screening purposes." J Clin Microbiol.

Hesselink, A. T., N. W. Bulkmans, et al. (2006). "Cross-sectional comparison of an automated hybrid capture 2 assay and the consensus GP5+/6+ PCR method in a population-based cervical screening program." J Clin Microbiol 44(10): 3680-3685.

Hesselink, A. T., D. A. Heideman, et al. (2010). "Comparison of the clinical performance of PapilloCheck human papillomavirus detection with that of the GP5+/6+-PCR-enzyme immunoassay in population-based cervical screening." J Clin Microbiol 48(3): 797-801.

Hesselink, A. T., A. J. van den Brule, et al. (2004). "Comparison of hybrid capture 2 with in situ hybridization for the detection of high-risk human papillomavirus in liquid-based cervical samples.” Cancer 102(1): 11-18.

Jacobs, M. V., P. J. Snijders, et al. (1997). “A general primer GP5+/GP6(+)-mediated PCR-enzyme immunoassay method for rapid detection of 14 high-risk and 6 low-risk human papillomavirus genotypes in cervical scrapings.” J Clin Microbiol 35(3): 791-795.

Josefsson, A. M., P. K. Magnusson, et al. (2000). "Viral load of human papilloma virus 16 as a determinant for development of cervical carcinoma in situ: a nested case-control study." Lancet 355(9222): 2189-2193.

Karlsen, F., M. Kalantari, et al. (1996). "Use of multiple PCR primer sets for optimal detection of human papillomavirus.” J Clin Microbiol 34(9): 2095-2100.

Katki, H. A., W. K. Kinney, et al. (2011). “Cervical cancer risk for women undergoing concurrent testing for human papillomavirus and cervical cytology: a population-based study in routine clinical practice.” Lancet Oncol 12(7): 663-672. 
Khan, M. J., P. E. Castle, et al. (2005). "The elevated 10-year risk of cervical precancer and cancer in women with human papillomavirus (HPV) type 16 or 18 and the possible utility of type-specific HPV testing in clinical practice.” J Natl Cancer Inst 97(14): 1072-1079.

Kinney, W., M. H. Stoler, et al. (2010). "Special commentary: patient safety and the next generation of HPV DNA tests." Am J Clin Pathol 134(2): 193-199.

Kleter, B., L. J. van Doorn, et al. (1999). “Development and clinical evaluation of a highly sensitive PCR-reverse hybridization line probe assay for detection and identification of anogenital human papillomavirus.” J Clin Microbiol 37(8): 2508-2517.

Lorincz, A. T., P. E. Castle, et al. (2002). "Viral load of human papillomavirus and risk of CIN3 or cervical cancer." Lancet 360(9328): 228-229.

Lorincz, A. T. and J. S. Smith (2006). Sexually transmissible viral pathogens: Human papillomaviruses and herpes simplex viruses. Nucleic acid testing for human disease. A. T. Lorincz and J. S. Smith, Taylor Francis CRC Press: $244-273$.

McCrory D, M. D., Bastian L (1999). Evaluation of cervical cytology. Evidence Report/Technology Assessment No. 5. Rockville/MD, USA, Agency

for Health Care Policy and Research.

Meijer, C. J., J. Berkhof, et al. (2009). "Guidelines for human papillomavirus DNA test requirements for primary cervical cancer screening in women 30 years and older.” Int J Cancer 124(3): 516-520.

Mittendorf, T., M. Nocon, et al. (2007). “Assessment of effectiveness and cost-effectiveness of HPV testing in primary screening for cervical.” GMS Health Technol Assess 3: Doc08.

Molden, T., I. Kraus, et al. (2005). "Comparison of human papillomavirus messenger RNA and DNA detection: a crosssectional study of 4,136 women $>30$ years of age with a 2-year follow-up of high-grade squamous intraepithelial lesion." Cancer Epidemiol Biomarkers Prev 14(2): 367-372.

Qiao, Y. L., J. W. Sellors, et al. (2008). “A new HPV-DNA test for cervical-cancer screening in developing regions: a cross-sectional study of clinical accuracy in rural China.” Lancet Oncol 9(10): 929-936.

Qu, W., G. Jiang, et al. (1997). "PCR detection of human papillomavirus: comparison between MY09/MY11 and GP5+/ GP6+ primer systems.” J Clin Microbiol 35(6): 1304-1310.

Quigley, N. B., N. T. Potter, et al. (2011). "Rate of detection of high-risk HPV with two assays in women $>/=30$ years of age." J Clin Virol 52(1): 23-27.

Quint, W. G., S. R. Pagliusi, et al. (2006). "Results of the first World Health Organization international collaborative study of detection of human papillomavirus DNA.” J Clin Microbiol 44(2): 571-579.

Rebolj, M., J. Bonde, et al. (2011). "Human papillomavirus testing in primary cervical screening and the cut-off level for hybrid capture 2 tests: systematic review." BMJ 342: d2757.

Sankaranarayanan, R., R. Chatterji, et al. (2004). "Accuracy of human papillomavirus testing in primary screening of cervical neoplasia: results from a multicenter study in India.” Int J Cancer 112(2): 341-347.

Saslow, D., C. D. Runowicz, et al. (2002). “American Cancer Society guideline for the early detection of cervical neoplasia and cancer.” CA Cancer J Clin 52(6): 342-362.

Schiffman, M., M. J. Khan, et al. (2005). "A study of the impact of adding HPV types to cervical cancer screening and triage tests.” J Natl Cancer Inst 97(2): 147-150.

Schiffman, M., N. Wentzensen, et al. (2011). "Human papillomavirus testing in the prevention of cervical cancer." J Natl Cancer Inst 103(5): 368-383.

Schmitt, M., I. G. Bravo, et al. (2006). “Bead-based multiplex genotyping of human papillomaviruses.” J Clin Microbiol 44(2): 504-512.

Schmitt, M., V. Dalstein, et al. (2010). "Diagnosing cervical cancer and high-grade precursors by HPV16 transcription patterns." Cancer Res 70(1): 249-256. 
Snijders, P. J., A. J. van den Brule, et al. (2003). "The clinical relevance of human papillomavirus testing: relationship between analytical and clinical sensitivity.” J Pathol 201(1): 1-6.

Stoler, M. H., T. C. Wright, Jr., et al. (2011). "High-risk human papillomavirus testing in women with ASC-US cytology: results from the ATHENA HPV study.” Am J Clin Pathol 135(3): 468-475.

Szarewski, A., L. Ambroisine, et al. (2008). "Comparison of predictors for high-grade cervical intraepithelial neoplasia in women with abnormal smears.” Cancer Epidemiol Biomarkers Prev 17(11): 3033-3042.

van Duin, M., P. J. Snijders, et al. (2002). "Human papillomavirus 16 load in normal and abnormal cervical scrapes: an indicator of CIN II/III and viral clearance.” Int J Cancer 98(4): 590-595.

Wang, S. S., M. Schiffman, et al. (2003). "Seroprevalence of human papillomavirus-16, -18, -31, and -45 in a population-based cohort of 10000 women in Costa Rica." Br J Cancer 89(7): 1248-1254.

Wheeler, C. M., W. C. Hunt, et al. (2006). "Human papillomavirus genotypes and the cumulative 2-year risk of cervical precancer.” J Infect Dis 194(9): 1291-1299.

Wright, T. C., Jr., J. T. Cox, et al. (2002). "2001 Consensus Guidelines for the management of women with cervical cytological abnormalities.” JAMA 287(16): 2120-2129.

Wright, T. C., Jr., L. S. Massad, et al. (2007). "2006 consensus guidelines for the management of women with abnormal cervical cancer screening tests.” Am J Obstet Gynecol 197(4): 346-355.

Youens, K. E., G. A. Hosler, et al. (2011). "Clinical experience with the Cervista HPV HR assay: correlation of cytology and HPV status from 56,501 specimens.” J Mol Diagn 13(2): 160-166.

Zielinski, G. D., A. G. Bais, et al. (2004). "HPV testing and monitoring of women after treatment of CIN 3: review of the literature and meta-analysis." Obstet Gynecol Surv 59(7): 543-553. 